\title{
História Oral, prática futebolística e cidades no Brasil: conflitos e apropriações nas narrativas de ocupação dos campos de "futebol de várzea" de Belo Horizonte - MG
}

\author{
Bernardo Borges Buarque de Hollanda* \\ Raphael Rajão Ribeiro*
}

\section{Apresentação}

“... a memória é um fenômeno que nenhuma disciplina pode monopolizar"

(Assman, 2011).

* Professor-adjunto da Escola de Ciências Sociais, da Fundação Getúlio Vargas (FGV/CPDOC). Pós-doutor pela Fondation Maison des Sciences de L'homme (FMSH) de Paris (Bourse Hermès, 2009) e pela University of Birmingham (Rutherford Fellowship, 2018). É membro do conselho da International Oral History Association (IOHA) e editor das revistas Estudos Históricos e Words \& Silences. Suas áreas de interesse são: história social do futebol e torcidas organizadas, modernismo e vida literária no Brasil, cultura brasileira, crítica e interpretação, pensamento social e história intelectual. E-mail: Bernardo. Hollanda@fgv.br.

** Doutorando em História, Política e Bens Culturais na Escola de Ciências Sociais da Fundação Getúlio Vargas (FGV/CPDOC). É técnico nível superior em patrimônio cultural no Museu Histórico Abílio Barreto (MHAB), equipamento da Fundação Municipal de Cultura de Belo Horizonte. Suas áreas de interesse são: história social do futebol, em especial do futebol amador; culturas urbanas e patrimônio cultural. E-mail: raprajao@gmail.com. 


\section{O presente artigo procura contribuir com o dossiê "Cidade, persona-} gens e ocupaçóes dos espaços", com a introdução do debate em torno de experiências populares do futebol amador na regiáo metropolitana de Belo Horizonte (MG). Em âmbito mais amplo, tenciona-se primeiramente enquadrar futebol e História Oral no país, mostrando de que maneira as duas áreas correram em vias paralelas no Brasil entre as décadas de 1970 e o início do século XXI, até encontrarem pontos de sinergia e confluência nos últimos anos, através de pesquisadores dedicados a narrativas das práticas esportivas brasileiras (Toledo, 2002, p. 133).

Se pode-se afirmar que ambas tiveram em comum uma posição secundária, para não dizer subalterna, nos domínios da Historiografia e das Ciências Sociais, também é possível postular que os estudos históricos dos esportes e o emprego da metodologia da História Oral souberam se legitimar e construir seus próprios espaços ao longo das décadas no interior do campo científico nacional, legitimidade e construçáo estas capazes de fazer com que o paralelismo de seu desenvolvimento proporcionasse momentos de intersecção, cruzamento e encontro.

Este artigo apresenta de modo retrospectivo uma série de iniciativas coletivas e institucionais desenvolvidas no Brasil, que tiveram por objetivo a criação de registros orais para documentar e dar suporte à memória esportiva de seus diversos atores, entre eles, atletas, treinadores, dirigentes e espectadores. Embora muitas vezes com intenções pré-científicas, a cargo de instituições de conservação e guarda como museus e outras instituições de cunho patrimonial, como também de secretarias de governo ou de centros de documentação pública, tais iniciativas aproximaram-se em período mais recente dos métodos e dos princípios estabelecidos pela História Oral.

A finalidade colocada por essa corrente historiográfica consistiu em estabelecer critérios confiáveis, do ponto de vista da ciência, na coleta de histórias de vida e no estudo de temas relacionados a diversas modalidades desportivas.

Após apresentar, de maneira panorâmica e não exaustiva, o conjunto de pesquisas que associaram a gravaçáo de relatos de personagens do universo esportivo à consolidação de fontes orais no país, o artigo detém-se num caso empírico específico associado ao tema do presente dossiê, e vinculado à experiência urbana associativa do futebol, opção de recorte que se deve à popularidade e à inegável relevância social da prática futebolística no país. Com foco nas entrevistas de integrantes de equipes varzeanas, apresenta-se um estudo de caso, com depoimentos coletados durante o processo de registro patrimonial do futebol amador na cidade de Belo Horizonte, o sexto município mais populoso do Brasil, em pesquisa conduzida e acompanhada de perto por um dos autores.

Por meio desse caso, tenciona-se demonstrar de que modo, para além do futebol profissional masculino de alto rendimento, alvo de ampla, intensa e diária cobertura dos meios de comunicação de massa, o emprego da História Oral con- 
tém especial utilidade como método e como fonte para a reconstituição da prática futebolística em outras esferas da vida coletiva. Tal ponto de observaçáo permite o descentramento dos discursos monotemáticos do jornalismo esportivo, feitos em torno dos grandes clubes e das narrativas da Seleçâo Brasileira masculina, esta última dotada de projeção nacional e internacional.

A ênfase no futebol de matriz comunitária não profissional, tal como definida pelo antropólogo Arlei Damo, dá insumos para a percepção da pluralidade dos agentes, para as práticas citadinas cotidianas e para a apreensão da multiplicidade das experiências de vida, conformadoras dos mecanismos associativos de esporte e lazer nos espaços urbanos das grandes metrópoles:

Entre a matriz espetacularizada e a bricolada existe ao menos uma modalidade de futebol, vinculada ao tempo de lazer dos seus praticantes, realizada em espaços mais padronizados do que a bricolagem, mas sem a ortodoxia do sistema FIFA-IB. Talvez o que melhor caracterize o futebol intermediário - em boa parte do Brasil, ao menos de São Paulo em direção ao Sul é chamado de "futebol de várzea" - é a presença de quase todos os componentes do espetáculo, mas diferindo em escala... O circuito comunitário não exige dos atletas o mesmo capital corporal do profissionalismo, mas as fronteiras não são, de qualquer modo, tão porosas quanto nas configuraçōes bricoladas. (Damo, 2006, p. 13-14).

No cerne do trabalho, são examinadas as narrativas acerca das negociações de aquisição, manutenção e perda da posse dos campos de jogo, em áreas públicas da zona metropolitana da capital de Minas Gerais, por parte dos clubes dedicados a essa vertente amadora da modalidade. Para tanto, a ênfase recai nos discursos e nas operaçôes de memória acerca dos episódios centrados nas estratégias de garantia dos futebolistas e de suas agremiaçóes amadoras, com vistas a uma delimitação territorial para o desenvolvimento de atividades esportivas e lúdicas numa grande cidade brasileira.

A fim de alcançar o objetivo proposto, o artigo a seguir estrutura-se em três partes. Na primeira, mostra-se o contexto de introdução, emergência e afirmação da História Oral no país no decorrer das cinco últimas décadas. Procura-se abordar as iniciativas pioneiras de pesquisadores e instituiçóes que se associaram para desenvolver atividades voltadas a essa técnica de levantamento de fontes, a partir do último quarto do século XX.

Já a segunda parte dedica-se a entender de que forma os estudos dos esportes, e do futebol em particular, adquiriram espaço no interior da academia e das Ciências Sociais dos anos 1970 em diante, apresentando uma trajetória simultânea à da História Oral no Brasil. Propóe-se o levantamento de um conjunto de 
iniciativas institucionais e acadêmicas que se valeram de entrevistas memorativas dos atores esportivos, especialmente dos atletas e futebolistas, para a criação de dados de pesquisa histórica baseadas na subjetividade dos relatos orais e das recordaçóes pessoais.

A terceira e principal parte reconstitui, com base em gravaçóes em áudio, os esforços de clubes amadores da capital mineira para a manutenção dos direitos de uso de seus campos de futebol na cidade. Trata-se de uma abordagem da "interdependência conflituosa", para dialogar com Alessandro Portelli (2010, p. 131), que se coloca aos futebolistas em meio a negociaçóes reiteradas com o poder público municipal e em face dos interesses da especulação imobiliária na aquisição desses terrenos.

Visa-se, assim, uma apresentação que dê a conhecer o potencial de aplicação do método da História Oral no conhecimento da polifonia nas práticas e representaçôes futebolísticas no país. $\mathrm{Na}$ mesma proporção, procura-se enfatizar, sobretudo ao leitor não especializado, o estado da arte dos estudos futebolísticos no Brasil, em especial os aspectos que ultrapassam os chavóes associados às metáforas do "futebol-arte" e do "país do futebol", tal como o Brasil costuma ser reconhecido no exterior desde meados do século passado.

\section{Introdução e desenvolvimento da História Oral no Brasil}

A introdução institucional da História Oral no Brasil remonta a meados da década de 1970, mais precisamente ao ano de 1975, quando da criação do setor de História Oral, no interior do Centro de Documentação e Pesquisa de História Contemporânea do Brasil, conhecido pelo acrônimo CPDOC, da Fundação Getúlio Vargas (FGV), no Rio de Janeiro. Sua criação, uma iniciativa pioneira à época, sob os auspícios da Fundação Ford, consistiu na coleta de uma série de entrevistas e depoimentos de protagonistas das elites políticas brasileiras, de modo a servir de suporte ao acervo pessoal recém-constituído daquela instituição, calcada por sua vez na doação de fontes primárias por parte dos herdeiros de Getúlio Vargas, ex-presidente da República nos períodos de 1930-1945 e 1951-1954.

Os documentos - compostos de fotografias, cartas e outros manuscritos - doados pelos familiares do presidente e, em seguida, por seu corpo principal de ministros, necessitavam de informaçóes complementares e de elucidaçóes acerca da trajetória desses atores que apenas testemunhos e registros orais podiam fornecer. Com o auxílio da tecnologia da época, isto é, a fita cassete e o gravador portátil, a História Oral foi o recurso de que se valeram os pesquisadores então 
integrantes da equipe profissional do CPDOC para cobrir as lacunas necessárias à reconstituição da história brasileira contemporânea, em especial aquela que ia da Revolução de 1930 em diante.

Até então, os historiadores do país concentravam-se no estudo de fases pretéritas da vida nacional, como o período colonial (séculos XVI a XVIII) e o imperial (século XIX), deixando a República a cargo das interpretaçóes de sociólogos e cientistas políticos. A historiografia mais tradicional não acreditava que houvesse distanciamento temporal possível, nem documentos suficientes, para analisar a fase histórica republicana no século XX, que eles próprios testemunhavam e vivenciavam.

A proposta levada a cabo pelos cientistas sociais e historiadores do CPDOC era inédita na academia brasileira, mas não era de todo isolada, pois recebia influência do contexto internacional, que assistia à quebra de paradigmas científicos e às transformações historiográficas em curso na década de 1970 .

Uma das vinculaçóes mais fortes desse grupo de pesquisadores do CPDOC, que se doutorava fora do país, dava-se com o universo intelectual dos historiadores franceses, em um período de mudanças conhecido na França pelos adventos da História do Tempo Presente e da Nova História, esta última correspondente à terceira fase da Escola dos Annales, capitaneada por Jacques Le Goff e Pierre Nora.

Em outros países, novos métodos, novas fontes e novos objetos também eram reclamados pelas geraçóes de historiadores que emergiam. A História aproximava-se de disciplinas como a Antropologia, a Comunicação e a Linguística, produzindo perspectivas diferenciadas na abordagem de seus temas principais de interesse. Na Itália, por exemplo, assistia-se à emergência da Micro-História, com estudos qualitativos, em escala reduzida, capazes de contornar as temáticas canônicas até então consagradas, baseadas em séries quantitativas e em estruturas econômico-sociais.

Nos Estados Unidos, a chamada "virada linguística” espraiou-se por boa parte das Ciências Humanas e questionou em chave hermenêutica alguns dos padrôes de objetividade e de cientificidade postulados nas Ciências Sociais até então. A Teoria da Literatura lançava uma série de desafios aos usos da narrativa pelos historiadores, por meio de um questionamento à chamada opacidade da linguagem na estruturação positivista do texto historiográfico.

$\mathrm{Na}$ Inglaterra, por seu turno, viu-se a ascensão de correntes como os Estudos Culturais e a História Social, no contexto histórico posterior à Segunda Guerra Mundial. Expoentes desta última corrente, a partir dos anos 1960, preconizaram uma "história vista de baixo", também chamada de "história dos vencidos", de cunho muitas vezes militante, no sentido de fazer eco e de "dar voz às minorias" (1992). Neste bojo, assistiu-se também à emergência da História Oral, 
a partir da publicação de um livro capital para a constituição da área: "A voz do passado", de Paul Thompson, publicado originalmente em 1978. Pode-se dizer que, de forma direta ou indireta, a influência dessa obra se fez sentir no Brasil no decorrer dos anos 1980.

Em 1992, o livro de Thompson foi traduzido para o português e teve impacto notável não só entre os pesquisadores do CPDOC, como entre os historiadores brasileiros de modo geral. Destarte, é possível observar que a História Oral disseminou-se para além do referido centro de pesquisa do Rio de Janeiro, desenvolvendo-se em outros espaços universitários como os sediados nos estados de São Paulo e de Santa Catarina, para ficar com dois exemplos reconhecidos, encabeçados pelos professores José Carlos Sebe Bom Meihy (USP) e Carlos Humberto Pederneiras Corrêa (UFSC), respectivamente.

O resultado desse processo de difusão de núcleos de pesquisa e de consolidação de programas de História Oral pode ser mais bem percebido ao longo da década de 1990, com a criação da Associação Brasileira de História Oral (ABHO), estruturada em encontros anuais, alternando-se por sua vez em nível regional e nacional. O surgimento da ABHO em 1994 nacionalizou e aglutinou uma série de pesquisadores com interesse em entrevistas e em relatos orais. Seu efeito previsível foi o adensamento não só quantitativo como qualitativo dessa área. Ainda no final daquele decênio, foi criada a Revista de História Oral, espaço importante para a interlocução e a publicação de artigos científicos em tal domínio.

Uma característica marcante do desenvolvimento da História Oral entre os historiadores brasileiros foi a participação destes nos fóruns situados fora do país. A adesão e a participação ativa na criação da Associação Internacional de História Oral (IOHA) em 1996 (Ferreira, 2006) se fizeram notar ao longo dos anos 2000, seja nas instâncias diretivas da entidade, seja na presença de pesquisadores brasileiros nos encontros internacionais bianuais, sendo seu segundo congresso realizado na cidade do Rio de Janeiro, em 1998.

A reflexão em torno das condições de produção das fontes orais levou igualmente à ampliação das pesquisas em História Oral no país, com a incorporação de outros estratos e grupos sociais como objeto empírico de análise. Os primórdios da disciplina no Brasil, vinculados ao núcleo original do CPDOC, foram marcados pelo interesse em torno de atores pertencentes às elites políticas nacionais, próximas das instâncias decisórias de poder e dos segmentos profissionais letrados. Uma vez aprofundadas as pesquisas com tal tipo de fonte, trouxe-se o questionamento sobre o enfoque historiográfico próximo ao da chamada história

1 Este autor, acrescente-se, orientou pesquisas em nível de pós-graduação que se voltaram para a metodologia e a trajetória da História Oral no Brasil, como o trabalho referencial de doutoramento de Ricardo Santhiago Corrêa de 2013. 
oficial, sem a devida consideraçáo pelos setores populares, marcados pela oralidade, pelas tradiçóes não-letradas e pela necessidade de estudos sobre os meandros operatórios da memória coletiva.

Nesse sentido, uma exceção exemplar no meio acadêmico foi o trabalho de Ecléa Bosi, professora do departamento de Psicologia Social, com pessoas idosas, residentes da cidade de São Paulo, em sua tese de doutorado do início dos anos 1970, publicada em livro no final daquele decênio. Intitulada "Memória e sociedade: lembrança de velhos", a pesquisa de Bosi, reeditada em 1994, inspirou-se por sua vez nos enquadramentos durkheimianos da memória, conceituados por Maurice Halbwachs, para tratar da vivência geracional e da experiência individual de um conjunto de senhoras e senhores residentes na capital paulistana no decurso do século XX.

Ao lado da referência a Halbwachs, outro marco teórico influente na conformação da História Oral no Brasil foi o pensamento do sociólogo austríaco Michael Pollak, que teve dois artigos publicados em português pela Revista Estudos Históricos, da FGV: "Memória, esquecimento, silêncio" (1989) e "Memória e identidade social" (1992). Em razão de seu aporte teórico, ambos os textos tiveram repercussão na comunidade de historiadores e cientistas sociais brasileiros, sendo citados de maneira constante na elaboração de pesquisas no país nos últimos trinta anos.

Além das controvérsias em torno das histórias de vida das classes populares versus as de setores das elites, também das interaçóes intersubjetivas ao redor do par entrevistador-entrevistado ou da polarização entre personalidades públicas versus sujeitos anônimos, uma discussão importante no meio nacional durante os anos 1990 dizia respeito ao critério de definição e, por conseguinte, de atuação dos praticantes da História Oral. Em termos conceituais, o debate se dividiu em três vertentes: aqueles que a veem como técnica, os que a entendem como disciplina, e ainda os adeptos da História Oral como metodologia.

Esse debate em torno da delimitação da História Oral foi colocado no Brasil pelas pesquisadoras Marieta de Moraes Ferreira e Janaína Amado, em uma coletânea seminal, lançada em 1996, que alcançaria oito ediçóes em dez anos: "Usos \& abusos da História Oral" (a edição consultada por nós é a de 2006). Trata-se de uma antologia com cinco eixos de questóes caras à reflexão teórico-metodológica, tendo por base a seleção dos textos considerados mais importantes em língua estrangeira, particularmente o inglês, o espanhol, o francês e o alemão, dedicados a pensar o assunto. A coletânea seria a primeira de uma série lançada por Ferreira no sentido da inserção teórica e metodológica da historiografia brasileira no interior da História Oral em seu momento de institucionalização e de internacionalização com a criação da IOHA em 1996.

Uma das diferenças identificadas pelas referidas autoras na apropriação da 
História Oral no Brasil vis-à-vis sua implantação em outros países concerne aos espaços de prática dessa ferramenta. Nos Estados Unidos, por exemplo, e em outros países anglo-saxóes, a utilização dos relatos orais foi além do âmbito universitário e soube se enraizar em instituiçóes como fundações, bibliotecas, museus e outras instituiçóes congêneres de arquivo e documentação. Ainda nesses países, minorias e movimentos sociais se apropriaram da técnica de gravação de depoimentos para constituir o seu próprio acervo e para demarcar a sua própria afirmação identitária. No Brasil, embora também existente, tal característica fez-se sentir com menos intensidade em fóruns como a $\mathrm{ABHO}$, cuja participação foi eminentemente composta por professores e pesquisadores universitários, procedentes das diversas regióes do país.

Além dos elementos institucionais, aspectos técnicos da metodologia foram desenvolvidos por Verena Alberti. Uma das primeiras questóes debatidas no quadro de uma pesquisa de História Oral diz respeito à definição do Roteiro de Entrevista. A seu juízo, esse consiste no passo primordial e, com base nele, a elaboração e a formulação das questôes que norteiam a preocupação central dos pesquisadores podem vir a ser estruturadas (Alberti, 2004, 2011, 2012).

O delineamento de um guia geral de perguntas formulado por Alberti procura seguir uma tradição metodológica da experiência do CPDOC com fontes orais, iniciada em meados dos anos 1970. Para tanto, adotam-se os métodos de "histórias de vida" e "histórias temáticas", em que o Roteiro é montado de modo a permitir um mínimo encadeamento cronológico na rememoração dos fatos. Longe de ser uma camisa de força, o que seria um contrassenso metodológico, a biografia do entrevistado ou o tema de que tratará são percorridos deixando-o à vontade para recontar suas recordaçóes segundo seu próprio fluxo de memória.

A metodologia da História Oral orienta-se, pois, em torno das "histórias de vida" e das "histórias temáticas". Ambas requerem uma estruturação tripartite, assim sequenciada: 1) A preparação da entrevista, com o levantamento de informaçôes e a montagem do Roteiro; 2) A gravação do depoimento, filmada e gravada em áudio, como backup; 3) A transcrição, a conferência de fidelidade, a análise do material colhido e o posterior arquivamento.

Conforme sumariza, em texto de balanço, a historiadora Ângela de Castro Gomes:

...no Brasil do século XXI, a metodologia de história oral alcançou sua maturidade. Pensando assim, não há dúvida de que um dos instrumentos mais importantes e exitosos na luta pela afirmação da metodologia foi a formação de uma Associação Brasileira de História Oral, em 1994. A mobilização e organização de seus praticantes por meio dessa associação foi decisiva para o fortalecimento dos argumentos que defendiam sua 
especificidade e valor e, no mesmo movimento, conformavam práticas de pesquisa que demarcavam o que seria conhecido como metodologia de história oral no Brasil. Tratando-se de uma fonte que é construída intencionalmente durante o processo de pesquisa, e que é construída de forma dialógica - porque envolve o próprio sujeito pesquisado além do pesquisador -, foi preciso tempo e debate para chegar a acordos sólidos. (2014, p. 164-165).

\section{"Futebol é cultura": abordagens pré-científicas, institucionais e acadêmicas da memória esportiva}

"coisa para todos, mas por encobrir uma diversidade de significados sob um mesmo conjunto de significantes"

(Portelli, 2010).

A seção acima dedicou-se a recapitular as vicissitudes de implantação da História Oral no Brasil, em um arco histórico abrangendo quase cinquenta anos, desde a sua introdução no final do século passado. O presente tópico, por sua vez, procura mostrar de que maneira os Estudos do Esporte em geral, e do futebol em especial, relacionaram-se a esta proposta metodológica, em período concomitante, isto é, durante a vigência dos anos 1970 a 2010.

À primeira vista, pode-se considerar que a aplicação de tal método no campo esportivo foi lenta e é ainda hoje tímida. Um levantamento junto aos congressos anuais da $\mathrm{ABHO}$ e às publicaçóes semestrais no periódico científico que lhe é correspondente não parece muito alvissareiro no estabelecimento de sinergias. Sáo poucos os trabalhos acadêmicos apresentados nos encontros citados que fazem referência a práticas e representaçóes do esporte, na mesma proporção em que o número de títulos publicados na revista com esse tema é mínimo.

Em 25 anos de existência da Associação, cinco simpósios temáticos foram organizados com a tematizaçáo explícita do Esporte. Em 2012, registrou-se o grupo de trabalho "Futebol, narrativas orais e memória", que debateu pesquisas na área durante o XI Encontro Nacional de História Oral, realizado no Rio de Janeiro. Já em 2018, na cidade de Campinas, esse mesmo painel foi reeditado, por ocasião da décima quarta edição do mesmo evento. No ano anterior, 2017, o XII Encontro Regional de História Oral, realizado por seu turno na cidade de Belo Horizonte, acolheu um simpósio temático com proposta análoga, intitulado "História do esporte e das práticas corporais".

Além dos três acima mencionados, acrescentam-se ainda mais dois, com o 
mesmo título, "História oral e práticas corporais e esportivas", realizados durante o IX Encontro Regional Sul de História Oral, em 2017 e o XIII Encontro Nacional de História Oral, em 2016, ambos na cidade de Porto Alegre.

Quanto à revista, o número é ainda menos expressivo. Ao compulsar a totalidade dos números e dos volumes do periódico Revista História Oral, existente desde 1998, localizou-se ao longo de 20 anos um único artigo publicado, no ano de 2017, com o título de "Futebol, memória e relatos orais: a trajetória de ex-jogadores da Seleção Brasileira e as narrativas memorialísticas das Copas do Mundo FIFA entre 1954 e 1982”, escrito por Bernardo Borges Buarque de Hollanda.

Além desse texto, uma outra publicação encontrada foi uma entrevista com o ex-atleta olímpico Sinibaldo Gerbasi, medalhista brasileiro nos Jogos Sul-americanos e Pan-americanos entre os anos 1930 e 1950. Gerbasi foi entrevistado já em idade avançada por pesquisadores de atletismo da Universidade Estadual Paulista (UNESP) - Fernando Paulo de Rosa Freitas e Sara Quenzer Matthiesen e a publicação no periódico saiu em 2010, com a chamada no título de "Histórias do salto com vara no Brasil".

Trabalhos acadêmicos stricto sensu, em nível de mestrado e de doutorado, também não costumam recorrer à História Oral para estudar as práticas esportivas até o momento. Ainda que muitas se valham de entrevistas, não se identifica uma filiação específica dos pesquisadores ao método. Uma honrosa exceção entre teses de doutoramento foi a de Marcel Tonini, defendida em 2016 no Departamento de História da Universidade de São Paulo (USP), sob orientação de José Sebe Bom Meihy.

A propósito, este último autor, citado na seção anterior, foi um nome pioneiro associado tanto à metodologia da História Oral quanto à introdução dos estudos futebolísticos no país. Já o trabalho de Tonini, voltado ao exame de uma questão do futebol contemporâneo, qual seja, a circulação de atletas no Brasil e na Europa e o fenômeno do racismo nos estádios, denominou-se "Dentro e fora dos gramados: histórias orais de vida de futebolistas brasileiros negros no continente europeu”.

Diante desse cenário, pode-se perguntar: a que se deve a baixa participação e incidência dos especialistas de Estudos do Esporte na História Oral no Brasil? Em primeiro lugar, um aspecto a considerar concerne ao próprio estatuto científico da pesquisa sobre o campo esportivo no Brasil. Originário das Escolas de Educação Física, foi apenas a partir dos anos 1970 que o estudo das práticas esportivas começou a ser investigado no âmbito das Ciências Sociais, extrapolando suas fronteiras iniciais, confinadas à biologia e à fisiologia corporal.

Vale enfatizar, a escolha por "prática esportiva" é aqui intencional, pois ultrapassa a noção de campo condicionada pelo termo "esporte". Nesta linha de raciocínio, segue- a observação do historiador britânico Peter Burke: 
'Práticas' é um dos paradigmas da Nova História Cultural: a história das práticas religiosas e não da teologia, a da história da fala e não da linguística, a história do experimento e não da teoria científica. Graças a essa virada em relação às práticas, a história do esporte, que antes era tema de amadores, tornou-se profissionalizada, um campo com suas próprias revistas, como International Journal for the History of Sport. (2008, p. 78).

Entre as ciências sociais, a disciplina que acolheu de início a temática esportiva, particularmente a futebolística, foi a Antropologia Social, em sua vertente da Antropologia Urbana, no decorrer dos anos 1970 e 1980. A acolhida dos antropólogos possivelmente advém da valorização dos chamados "temas menores", tais como ficaram vinculados os estudos do futebol no imaginário científico nacional do final do século XX. A despeito da popularidade do assunto no país, durante décadas essa prática esportiva foi vista como de menor importância na academia, com baixa reputação frente aos domínios ditos "sérios", próprios da economia política e caros ao universo do trabalho, em sua oposição dicotômica à ideia de lazer (DaMatta, 1982).

Assim, embora desde os anos 1980 a historiografia brasileira tivesse assimilado influências internacionais, com a ampliação de seu leque de objetos e com a legitimação de novos territórios de pesquisa, a ensejar inclusive a criação de um famoso bordão editorial "tudo é História", e a publicar livros introdutórios como "História política do futebol brasileiro" de Joel Rufino dos Santos (1981), é tão somente no final dos anos 1990 que os historiadores do país começam a desenvolver os primeiros trabalhos acadêmicos de maior fôlego sobre a temática, como o de História Social desenvolvido por Leonardo Pereira, "Footballmania" em 2001.²

Em segundo lugar, a presença diminuta da inter-relação entre Esportes e História Oral no contexto universitário nacional tem a ver com uma das particularidades do seu lugar na memória institucional. Não caberiam aqui prolegômenos ao estudo do futebol no Brasil, mas a pouca aderência, para não dizer resistência inicial aos esportes nos domínios das Ciências Sociais e da Historiografia, permite observar que seu efeito foi de deslocamento do ambiente universitário, com a introdução da História Oral do futebol brasileiro nos anos 1960 e 1970 sendo

2 Por suposto, o cenário acadêmico na atualidade é outro. As ciências humanas e sociais assistiram a um notável incremento e diversificaçáo na produçáo bibliográfica, de modo que seria impossível aqui listar e enumerar tal crescimento qualitativo e quantitativo. Destacamos tão somente, à guisa de exemplo, o livro ensaístico de José Miguel Wisnik, "Veneno remédio: o futebol e o Brasil". Nele, o escritor retoma a tradição de ensaios sobre futebol e filia-se em parte a uma tradiçáo interpretativa culturalista, iniciada por Gilberto Freyre nos anos 1930 e modificada por Roberto DaMatta nos anos 1980. 
privilegiada por instituiçóes como os museus.

É o caso em particular do Museu da Imagem e do Som (MIS), inaugurado e estabelecido nas duas principais cidades brasileiras: Rio de Janeiro, no ano de 1965, e São Paulo, no ano de 1970. Graças a políticas curatoriais voltadas à gravação de depoimentos de personalidades da cultura brasileira, tanto na música quanto nas artes, no teatro e no cinema, ambas as instituiçóes estenderam ao futebol a condição "cultural" e "artística", legitimando a sua inclusão no espaço museológico com a gravação sonora e a guarda desses registros orais.

Foi assim que, entre as décadas de 1960 e 1980, esses museus audiovisuais criaram duas séries de entrevistas com grandes futebolistas brasileiros: "Depoimentos para a posteridade" e "Memória do futebol", respectivamente (Mesquita, 2009). Conduzidas por expoentes do jornalismo esportivo do Rio de Janeiro e de São Paulo, por vezes em parceria com pesquisadores egressos de universidades, as entrevistas não chegaram a seguir o padrão estrito da metodologia da História Oral, mas propiciaram a constituição de um acervo de depoimentos com histórias de vida narradas por ídolos esportivos nacionais, a exemplo de Pelé, Garrincha e Djalma Santos, entre dezenas de outros.

Décadas depois, já nos idos de 2010, uma aproximação maior da área acadêmica com os museus levou à constituição de novos acervos futebolísticos, desta feita mais afinados com os padróes metodológicos preconizados pela História Oral elaborada em manuais e livros acadêmicos (Alberti, 2004). Isto aconteceu, em especial, no tocante ao rigor do método, a saber, as etapas de preparação, condução, análise e conservação das fontes primárias engendradas pelas entrevistas.

Referimo-nos aqui a dois projetos interinstitucionais levados a cabo pelo supracitado CPDOC da Fundação Getúlio Vargas, e desenvolvidos com vistas a constituir um banco de dados para o Centro de Referência do Futebol Brasileiro (CRFB), órgão vinculado ao Museu do Futebol, equipamento público subordinado ao governo do estado de São Paulo e inaugurado no ano de 2008.

A primeira pesquisa, realizada entre 2011 e 2012, denominou-se "Futebol, memória e patrimônio" e consistiu na gravação de 120 horas de depoimentos de 54 ex-futebolistas que representaram o país, por meio da Seleção Brasileira, nas Copas do Mundo FIFA, no decorrer de oito ediçóes, entre o Mundial de 1954 e o de 1982. Já a segunda pesquisa, feita entre 2014 e 2015, foi chamada de "Territórios do torcer” e teve por escopo entrevistas com lideranças e fundadores de torcidas organizadas de futebol na cidade de São Paulo, com 60 horas gravadas, para pouco mais de duas dezenas de depoentes (Hollanda, 2017).

A História Oral vem assumindo, pouco a pouco, um vínculo mais direto com universidade. Isto pode ser destacado em projetos como o da professora Katia Rubio, da Escola de Educação Física da USP, em torno da participação de atletas nas edições quadrienais dos Jogos Olímpicos de Inverno, organizados pelo Comitê 
Olímpico Internacional (COI), chamado: "Memórias olímpicas por atletas olímpicos brasileiros".

Além dessa pesquisa, vale mencionar a existência do precursor Centro de Memória do Esporte (CEME), criado no final dos anos 1990, na Escola de Educação Física da Universidade Federal do Rio Grande do Sul (UFRGS). Esse centro foi responsável por constituir uma referência memorialística para os estudiosos das práticas esportivas, indo além do tradicional foco dispensado ao futebol profissional em detrimento das modalidades amadoras de esporte.

Sem a pretensão da exaustão, pois um levantamento mais detido pode apontar a existência de outros núcleos e espaços de pesquisa franqueados à História Oral, o propósito desta seçâo foi mostrar o espaço relativamente pequeno que tal método ocupa entre acadêmicos voltados ao estudo da memória e da história dos esportes no Brasil, sugerindo um potencial ainda pouco explorado no país.

Passemos a seguir à terceira e principal parte deste artigo, com o aprofundamento do estudo de caso que articula não só História Oral e estudo do futebol, mas especialmente a tríade temática que enfeixa o dossiê, interligando a metrópole de Belo Horizonte a seus personagens futebolísticos e à ocupação de espaços nas franjas da cidade.

\section{Os campos de várzea e suas narrativas: protagonismo popu- lar nos relatos orais sobre a prática futebolística amadora na cidade de Belo Horizonte}

A realização de grandes eventos no Brasil, notadamente a Copa do Mundo Masculina de Futebol de 2014 e as Olimpíadas do Rio de Janeiro de 2016, foi ocasiáo para a produção de uma série de reflexóes acadêmicas sobre o fenômeno esportivo em sua vertente mais espetacularizada, ligada a instituiçóes reguladoras e de gigantescos orçamentos como a Federaçáo Internacional de Futebol (FIFA) e o COI. ${ }^{3}$ Passadas as temporadas de visibilidade para as mega competiçóes, novas agendas de pesquisa sobre os esportes emergiram, com foco em expressōes locais e de menor escala, pouco abordadas pelas coberturas midiáticas (Benitez; Rodrigues, 2018).

3 Entre 2013 e 2016, foram editados diversos dossiês em revistas acadêmicas e coletâneas em formato de livro no Brasil, nas mais diferentes áreas das humanidades. A título de exemplo, citamos as seguintes publicações: Revista Tempo, Niteroi, v. 19, n. 34, 2013; Revista USP, São Paulo, n. 99, 2013; Revista USP, São Paulo, n. 108, 2016; “The Country of Football”, organizado por Paulo Fontes e Bernardo Buarque de Hollanda em 2014. 
Os novos estudos se articulam com debates acerca da diversidade cultural, de identidades regionais e do acesso a direitos sociais e civis. Tais pesquisas buscam ampliar a compreensão sobre o esporte e, mais especificamente, sobre o futebol para além de uma visão totalizante pautada em generalizaçóes, tão propaladas no autodeclarado "país do futebol". Ao concentrar-se em torno de grupos com pouca visibilidade e sobre os quais quase não foram produzidos registros, seja pelos órgãos oficiais ou pelas mídias, tais investigaçóes lançam mão, amplamente, da metodologia da História Oral.

O caso que será abordado nesta terceira e última seção do texto insere-se na emergência de tal agenda de pesquisas. Ademais, aponta para possibilidades de articulação entre produção acadêmica e promoção de políticas públicas, evidenciando a amplitude dos usos que a metodologia da História Oral alcançou no Brasil.

A série de depoimentos aqui examinada origina-se de uma iniciativa de identificação do patrimônio cultural em Belo Horizonte, a sexta maior cidade do Brasil, capital do estado de Minas Gerais. Tratou-se de uma ação da prefeitura local, articulada entre as áreas de cultura, esporte e lazer. Foram entrevistadas pessoas ligadas a agremiaçóes esportivas não profissionais que desenvolvem suas atividades há, pelo menos, cinquenta anos.

Tal estudo tinha por objetivo o reconhecimento do chamado "futebol de várzea” como patrimônio cultural de natureza imaterial do município. A realização de entrevistas de História Oral com antigos e atuais membros das entidades esportivas foi parte do processo de inventário da prática, que também envolveu pesquisas de arquivo e trabalhos de campo. No presente artigo trabalharemos com um total de 36 entrevistas temáticas com membros de 32 clubes diferentes. Como forma de indicar as potencialidades desse material, não apenas para políticas de patrimonialização, mas também para reflexóes acadêmicas da história do esporte e da história social, será abordado um tema específico que surgiu reiteradamente nos depoimentos.

Em que pese as narrativas sobre as trajetórias dos clubes perpassarem diversos assuntos, um tópico recorrente, que se apresentou como organizador das memórias daqueles informantes, refere-se à posse ou à perda do campo de jogo pelas entidades. Os eventos relativos a esse fato são centrais para a divisão do tempo, sendo importantes marcos de inflexôes positivas ou negativas para aquelas sociedades atléticas.

Dada sua relevância, consideramos pertinente o aprofundamento na análise sobre as maneiras como os eventos de conquista e perda dos campos de jogo são contados. Compreendemos assim que essas formas podem revelar sentidos que a ocupaçáo do espaço e a luta pelo direito à cidade assumem na experiência do futebol de várzea em Belo Horizonte. 
A territorialidade é elemento bastante evidente na configuração do futebol amador, não apenas em Belo Horizonte, mas em outras capitais do Brasil. ${ }^{4}$ Casos internacionais, como os dos clubes argentinos, também corroboram essa premissa (Frydenberg, 2013). A manutenção de um campo de jogo desempenha papel preponderante nessa relação, já que é aquele espaço que potencializa boa parte da articulação da prática com seu local de origem e com a comunidade que habita.

Levando-se em conta o conjunto de entrevistas examinadas, há uma recorrência não apenas da referência ao campo, mas da descrição de alguns eventos que são simbólicos da relação que os times estabelecem com esses locais. Aqui será feito de forma esquemática um exame das formas como esses momentos representativos são elaborados pelos depoentes, com destaque para como eles apresentam de forma reiterada cada um dos eventos: a conquista, a perda e a manutenção da área.

A análise desses relatos oferece um contraponto ao discurso predominante sobre os campos de futebol de várzea em Belo Horizonte e em outros centros urbanos nacionais. Tais narrativas, por diversas vezes veiculadas pelas mídias, mostram a prática como vítima da transformação das cidades, sofrendo intervençóes da atuação do poder público e da especulação imobiliária. Com a análise dos depoimentos dos atores envolvidos com essa modalidade esportiva, pretende-se demonstrar que há outras memórias possíveis sobre o fenômeno, as quais evidenciam atuação bem menos passiva frente às mudanças da capital mineira, conferindo-lhes maior protagonismo no processo.

\section{A posse do campo como um ato heroico de conquista}

Malgrado a ocupação de muitos campos ter acontecido há décadas, mais de cinquenta anos em alguns casos, momento no qual vários depoentes ainda não tinham relação com os clubes dos quais fazem parte, a narração sobre a forma como o espaço de jogo foi conseguido perpassa boa parte dos depoimentos colhidos. Esse ato fundante do vínculo da entidade com o território é uma das memó-

4 Há bibliografia considerável sobre o futebol amador em Belo Horizonte e em outros contextos, em boa parte dela, a questáo do espaço aparece de forma destacada. Podem ser citados trabalhos como a dissertação de Lívio Rodrigues Gomes, "Entre campos e cantos”; a tese de Mauro Myskiw, "Nas controvérsias da várzea"; a tese de Rosângela Duarte Pimenta, "Desvendando o jogo" e o livro de Diana Mendes Machado da Silva, "Futebol de várzea em São Paulo". 
rias que forjam a identidade das agremiaçóes. Seu tom, como será demonstrado, assume, no mais das vezes, contornos épicos.

Em muitas das narrativas, a transformação do cenário natural emerge como característica do ato fundador de apropriação do campo de jogo. $\mathrm{Na}$ fala de muitos dos entrevistados, esse evento adquire o tom de conquista, de desbravamento do espaço ainda não dominado. São comuns, nos depoimentos, episódios em que grupos de trabalhadores transformam inóspitos terrenos, à noite, após a jornada de trabalho, apenas com o uso de enxadas. Marco Antônio Coelho, mais conhecido como "Grapete", ligado ao Inconfidência Esporte Clube relatou sobre o esforço que testemunhou na infância onde: "Os caras chegavam aqui e jogavam terra aqui embaixo, aqui do lado do grupo. O barranco, lá de cima, vinha até quase aqui no meio do campo, foi terra demais que eles tiraram, ficou mais de três meses..." (Marco Antônio Coelho, 2016). Rosalvo Conceição Pereira, antigo presidente do Venda Nova Futebol Clube, relata episódio que teria se dado na década de 1930 e que ouvira de seu pai: "Eles subiram fazendo uma picada com enxadáo e picareta para fazer esse campo aqui. Esse campo aí, não tinha trator na época, foi tudo na mão, isso é tudo na mão (...)" (Rosalvo Conceição Pereira, 2016).

$\mathrm{O}$ emprego da força e a união entre os integrantes da agremiação emergem em muitos dos relatos. Um misto de heroísmo dos fundadores dos clubes e de demonstração de solidariedade comunitária. Em alguns casos, a capacidade de articulação dos membros dos times poderia viabilizar facilidades para a superação do obstáculo representado pela transformação do terreno. Como no caso em que conchavos com lideranças políticas locais garantiram a disponibilização de tratores para a abertura dos campos (Sebastião Bento de Souza, 2016).

Nem sempre a conquista se dava sobre o terreno inóspito, muitas vezes ela se convertia na supressáo de um adversário e na tomada do espaço de jogo de outra agremiaçáo que o possuíra no passado. Para tanto, contava a capacidade de organização do clube; não era ação violenta, mas de afirmação da relevância de um time mais ativo sobre outro que não se mostrava articulado o suficiente para manter ocupação regular do campo. Como narrado por Gemir de Souza, mais conhecido como "Miruca", que relatou a ocupação do campo de um clube que se desarticulava pelo Unidos da Brasilina, time do qual era fundador: "Aí nós viemos, como nós falávamos para a Grota. (...) Do Maravilha, Maravilha tinha acabado, nós ocupamos o campo, e o Brasilina tinha o nome, né, e o Maravilha não tinha, nós tínhamos nome, então nós ocupamos o campo" (Gemir de Souza, 2016). $\mathrm{Na}$ narrativa do antigo atleta e dirigente, o prestígio que o Unidos da Brasilina alcançara com sua performance esportiva - "nome" - o credenciava a substituir a agremiaçáo do Maravilha, que caminhava para a inatividade.

Em alguns casos, as duas situaçóes, superação das condiçóes do terreno e ocupação do espaço já reivindicado por outra agremiação, articulam-se nas mes- 
mas narrativas (José Maciel Campos, 2017).

Transformação da paisagem, articulação política, prevalência técnica e mobilização social são elementos que emergem das falas acerca da conquista de campos de jogo. Relatos que são contados para os novos membros e rememorados pela comunidade que se forma em torno dessas agremiaçóes dedicadas ao futebol amador. Tal como heróis lendários, os integrantes daquelas entidades dão demonstraçóes de força, de inteligência, de esperteza ou de persistência. Essas memórias, contudo, não são livres de privações que ponham em risco a vitória inicial.

\section{A trágica perda do campo}

As narrativas sobre o risco ou a perda do campo de jogo são igualmente recorrentes nos depoimentos. A precariedade da posse é algo bastante presente nos relatos. Situados em terrenos de propriedade do poder público ou de especuladores imobiliários, os clubes vivenciavam a incerteza constante de até quando permaneceriam no local, nada muito diferente das moradias decorrentes de ocupaçóes urbanas que deram origem a diversas favelas e bairros populares de Belo Horizonte e de outras tantas cidades brasileiras. Nessa medida, mais importante do que a perenidade da área, era a atenção constante e a busca de alternativas a todo o tempo.

Relatos de perdas de campo tendem a ter ares de tragédia. São momentos traumáticos da história da agremiação e marcam inflexão que muitas vezes explica a decadência do clube. É isso o que aponta o depoimento de Eliana da Conceição Costa, ex-secretária do Avante Futebol Clube, da favela do Aglomerado da Serra, filha da então presidente Maria da Conceição Silva.

Em seu depoimento, ela narra como que, em um dia qualquer, foi surpreendida pela açáo de agentes da prefeitura que retiravam as traves dos gols do campo que se situava bem próximo à sua casa. Os trabalhadores responsáveis apenas informaram cumprir ordens e que, caso desejassem reaver as traves, os integrantes do clube deveriam procurar as autoridades municipais. O espaço de jogo seria destinado à construção de uma escola. Mais tarde, as dirigentes do Avante descobririam que aquela obra fora encaminhada por meio da associação comunitária local, que submetera um abaixo-assinado aos órgãos públicos, lista que as próprias integrantes da agremiação teriam subscrito. Contudo, tal atitude só havia sido tomada porque a informação do líder comunitário responsável era de que se tratava de uma petição com outros fins, nada que interferisse na manutenção do campo (Eliana da Conceição Costa, 2017).

O caso do campo do Avante é exemplar do tom trágico que as perdas de campos assumem. Surpresa e sofrimento vivenciado pelos integrantes do clube, 
traição por parte de membros de outras associaçóes de bairro que rivalizam pelo reconhecimento da comunidade local, atuação arbitrária do poder público que não percebe o campo como bem da coletividade.

Narrativas de perdas de campo são recorrentes mesmo na memória de clubes que ainda mantém seus espaços. São usadas para explicar o desaparecimento de antigos adversários, perdas quase tão trágicas como a dos próprios espaços de jogo.

\section{Superação da perda como ação de resistência e motivo de orgulho}

Não foram poucos os casos narrados nas entrevistas em que houve resistência às tentativas de ocupação dos terrenos de jogo para outros usos, muitas vezes para construção de moradias por ocupantes que vivenciavam dificuldades semelhantes às que passavam os habitantes do lugar. Nesse caso, a reafirmação do sentido social do campo era fundamental.

Casos como a construção de uma escola em espaço destinado aos jogos poderiam ter outros desfechos, como ocorrera com o campo da Sociedade Esportiva São José Operário, uma agremiação do bairro Primeiro de Maio, cuja comunidade fazia sabotagens constantes aos trabalhos de demarcação da área. Como relatou Edval Gomes da Rocha, presidente do clube, tal evento teria se dado em fins da década de 1970, "Finalzinho, acho que de 78, 79 é que eles começaram a cogitar a ideia de fazer uma escola, em princípio era uma, agora são duas no terreno lá” (Edval Gomes da Rocha, 2017).

Após todo um dia de serviço dos topógrafos, que marcavam o terreno com estacas indicando o local de instalação das fundaçóes do edifício, os moradores do lugar, durante a madrugada, retiravam as balizas, retardando o andamento da obra. Sobre isso, Jorgeval Costa Lima, antigo goleiro do time, rememorou que: "A princípio, a gente fazia até molecagem, eles foram lá, na terraplanagem, eles colocavam aqueles piquetes de madeira... pra fazer, a gente ia lá e arrancava aqueles negócios." (Jorgeval Costa Lima, 2017). O ato de desobediência dos membros do clube teria pressionado o governo estadual a achar alternativa para a agremiaçáo, o que se deu por um acordo com reconhecida construtora da época: a Faial, pertencente ao mais famoso especulador imobiliário da cidade, Antônio Luciano. Para isso, contaram com a previsão legal de que todo novo empreendimento deveria reservar um percentual para área de uso comum. Nessa medida, graças à interferência dos membros, o time garantiu a continuidade de suas atividades com a manutenção de um lugar próprio, ainda que em bairro diverso. 
Para uma agremiação, manter-se ativa depois de longo período sem um campo tratava-se de motivo de orgulho e de afirmação da força e da união de seus membros. A superação de um destino quase certo para os clubes ligados ao futebol amador. Tal situação emergiu no relato de Guilherme Ferreira dos Santos, membro do Parque Riachuelo Futebol Clube, do bairro de mesmo nome, que perdeu seu espaço de jogo no final da década de 1950:

Tinha uma mania de chegar nos pênaltis e cantar: 'Quem falou/que o Parque morreu/ Se enganou/ O Parque não morreu/ Nem morrerá/ Deixa a danada da língua do povo falar/ Quem que falou?'; (risos) (...) Quando acabou o campo do Parque, os outros times que tinham campo falavam que o Parque tinha morrido. Aí a gente não aceitava, aí criou essa música. (Guilherme Ferreira dos Santos, 2016).

Sobreviver à perda do campo era um ato de resiliência por parte da agremiação. Contrariar as expectativas dos demais e seguir em atividade. Tal perspectiva é recorrente na fala dos clubes que seguem ou que passaram um tempo sem espaço de jogo. Essa situação é evocada como algo que reforça a capacidade de resistência da entidade, elemento de valorização da dedicação dos membros ao time.

Nessa perspectiva, nas construçốes de narrativas sobre si, as conquistas de novos campos ou a manutenção da equipe mesmo sem o espaço de jogo retoma a valorização dos membros da agremiação e de suas açóes. Se o terreno é elemento central da narrativa fundante, a superação de sua perda é ato de perseverança e reafirmação do valor do grupo. Trata-se de uma distinção em meio a tantas outras associaçôes que sucumbiram a esse evento.

Heroísmo, tragédia e resistência: três aspectos estruturantes das narrativas acerca da posse e da perda de campos. Em todas essas situaçóes, um elemento comum perpassa as histórias: a centralidade da atuação dos integrantes dos clubes. Ao contrário das análises costumeiras que povoam o imaginário acerca desses processos e das falas mais apressadas veiculadas pela imprensa, as quais atribuem o protagonismo do fenômeno a entes despersonalizados, como a especulação imobiliária ou a modernização das cidades, os depoentes indicam compartilhar de memória diversa sobre o ocorrido. Seus relatos são povoados de agentes responsáveis pelos acontecimentos, são membros de suas comunidades, políticos e empresários que mantinham com eles laços de reciprocidade.

Em suas falas, processos como a transformação da cidade movida pelas pressóes decorrentes da especulação imobiliária e da reconfiguração do tecido urbano conduzida pelo poder público, surgem não mais do que como pano de fundo de uma trama que é conduzida por amigos, vizinhos, parentes ou por eles mesmos. Atentos aos processos que ocorriam em seus bairros, buscavam identificar opor- 
tunidades para criação, manutenção ou substituição dos campos que abrigavam as agremiaçóes das quais faziam parte. Suas narrativas enfatizam o protagonismo que atribuem a si: orgulho, ressentimento, gratidão, nostalgia e tantos outros sentimentos, são elaborados a partir de interações muito palpáveis. Consideram que, cabia a eles constituir táticas e estratégias para reagir a eles, ainda que fenômenos maiores interferissem em seus destinos.

A recorrência de certas estruturas narrativas evidencia operaçóes de memórias de si e das instituiçóes às quais se vinculam. São tramas que organizam as trajetórias pessoais e das agremiaçóes de que fazem parte, reiterando traços identitários das comunidades e dos clubes. A presença de personagens externas, a exemplo de políticos e de especuladores imobiliários, associam esses relatos à própria história da cidade, conectando seus casos locais a acontecimentos e figuras que marcaram o imaginário de Belo Horizonte.

\section{Conclusão: para além da metáfora do "país do futebol"}

Este artigo foi elaborado com o propósito de compor um dossiê temático capaz de intercruzar as áreas de Estudos do Esporte e da História Oral, com uma abordagem da história social do futebol brasileiro nas cidades, à margem da matriz profissional e espectacularizada da modalidade. Para além dos clichês mobilizados quando se trata de tematizar o futebol nacional, buscamos um foco local mais preciso ao eleger nosso objeto de estudo. Junto à escolha do caso particular de uma cidade brasileira, a capital belo-horizontina, voltamo-nos para um ângulo de observação menos visado quando se aciona o imaginário nacional sobre o tema, no país e fora dele.

Mais do que clubes profissionais da elite futebolística, que chamam a atenção da opinião pública e mobilizam as paixóes de milhares de torcedores brasileiros, e mais do que o interesse regular devotado às estrelas da Seleção no calendário nacional, optamos por acompanhar atores vinculados ao chamado "futebol de várzea”, praticantes anônimos de competiçóes esportivas amadoras, próprias do lazer de parte expressiva das classes populares, em uma das capitais mais populosas do país.

Por intermédio de um conjunto de 36 entrevistas, detivemo-nos nos discursos enunciados por esses futebolistas acerca dos espaços concedidos e conquistados junto ao poder público para a prática dos seus torneios. Mostrou-se como o agenciamento desses campos na regiáo metropolitana passa por uma série de interaçóes, disputas e conflitos, materiais e simbólicos, que vedam ou facultam o acesso aos seus próprios campeonatos. Essa realidade litigiosa se ancora em situa- 
çôes concretas e em universos muitas vezes ignorados pela opiniáo pública, mas muito importantes para aqueles envolvidos no cotidiano de suas experiências com os jogos.

O propósito precípuo do artigo foi, pois, trazer a lume as narrativas desses futebolistas, salientando suas conotações ora heroicas, ora trágicas, ora resistentes, tal como as vivenciam no âmbito municipal. Para lograr tal intento, desenvolvido na terceira e principal parte deste artigo, foi feita, nas partes precedentes, uma contextualização prévia da introdução dos estudos esportivos no Brasil do final dos anos 1970, seguida de um cruzamento desse fenômeno com o advento da História Oral no meio acadêmico brasileiro. Esta última constitui ferramenta metodológica que vem sendo, tímida, mas progressivamente, incorporada, a fim de compreender dimensóes menos usuais da prática do futebol no país.

Procurou-se, ao fim e ao cabo, contestar a exclusividade da imagem festiva do Brasil como "país do futebol". Se esse nível de compreensão do senso comum acerca do etos nacional comporta facetas menos harmônicas, quando se passa de sua vertente "espetacularizada" para esferas comunitárias, é possível perceber de que maneira a realidade futebolística possui tensôes explicitas, vocalizadas nas narrativas dos seus protagonistas, dando a conhecer um cotidiano menos consensual do que aquele que se gosta de exibir ao mundo.

\section{Referências}

ALBERTI, Verena. Histórias dentro da História. In: PINSKY, Carla Bassanezi (Org.). Fontes históricas. São Paulo: Contexto, 2011.

. Manual de história oral. Rio de Janeiro: FGV Editora, 2004.

. Ouvir contar: textos em História Oral. Rio de Janeiro: FGV Editora, 2012.

ASSMAN, Aleida. Espaços da recordação: formas e transformações da memória cultural. Campinas: Editora da Unicamp, 2011.

BENITEZ, Allan Kardec Pinto Acosta; RODRIGUES, Francisco Xavier Freire. O futebol de várzea na comunidade São Gonçalo Beira Rio - Cuiabá/MT. Cuiabá: EdUFMT, 2018.

BOSI, Ecléa. Memória e sociedade: lembranças de velhos. São Paulo: Companhia 
das Letras, 1994.

BURKE, Peter. O que é história cultural? Rio de Janeiro: Zahar, 2008.

CORRÊA, Ricardo Santhiago. Método, metodologia, campo: a trajetória intelectual e institucional da História Oral no Brasil. Tese (Doutorado em História Social) USP, São Paulo, SP, 2013.

DAMATTA, Roberto. Esporte na Sociedade: Um Ensaio sobre o Futebol Brasileiro. In: DAMATTA, Roberto (Org.). Universo do Futebol: esporte e sociedade brasileira. Rio de Janeiro: Pinakotheke, 1982. p. 19-42.

DAMO, Arlei. Do dom à profissão: formação de futebolistas no Brasil e na França. São Paulo: Hucitec/Anpocs, 2007.

FERREIRA, Marieta de Moraes; AMADO, Janaína. Usos \& abusos da História Oral. Rio de Janeiro: FGV Editora, 2006.

FONTES, Paulo; HOLLANDA, Bernardo Buarque de (Org.). The country offootball: Politics, Popular Culture, and the Beautiful Game in Brazil. Londres: Hurst \& Company, 2014.

FREITAS, Fernando Paulo Rosa de; MATTHIESEN, Sara Quenzer. Histórias do salto com vara no Brasil: entrevistando Sinibaldo Gerbasi. Revista História Oral, Rio de Janeiro, v. 13, n. 1, p.123-140, 2010.

FRYDENBERG, Julio. História social del fútbol: del amateurismo a la profesionalización. Buenos Aires: Siglo XXI, 2013. p. 91-106.

GOMES, Ângela de Castro. Associação Brasileira de História Oral, 20 anos depois: o que somos? O que queremos ser? Revista História Oral, Rio de Janeiro, v. 17, n. 1, p. 163-192, 2014.

GOMES, Lívio Rodrigues. Entre campos e cantos: para uma sociologia do futebol amador. Dissertação (Mestrado) - UFMG, Belo Horizonte, MG, 2013.

HOLLANDA, Bernardo Borges Buarque de. Futebol, memória e relatos orais: a trajetória de ex-jogadores da Seleção Brasileira e as narrativas memorialísticas das Copas do Mundo FIFA 1954-1982. Revista História Oral, Rio de Janeiro, v. 20, n. 1, p. 101-123, 2017. 
- Os usos da História Oral no estudo do futebol: etapas metodológicas de uma experiência de pesquisa qualitativa com torcidas organizadas da cidade de São Paulo. Publicatio UEPG: Ciência Sociais e Aplicadas, Ponta Grossa, v. 25 n. 2, p. 187-201, 2017.

MESQUITA, Cláudia. Um museu para a Guanabara: Carlos Lacerda e a criação do Museu da Imagem e do Som (1960-1965). Rio de Janeiro: Folha Seca, 2009.

MYSKIW, Mauro. Nas controvérsias da várzea: trajetórias e retratos etnográficos em um circuito de futebol da cidade de Porto Alegre. Tese (Doutorado) - UFRGS, Porto Alegre, RS, 2012.

PEREIRA, Leonardo Affonso de Miranda. Footballmania: uma história social do futebol no Rio de Janeiro. Rio de Janeiro: Nova Fronteira, 2000.

PIMENTA, Rosângela Duarte. Desvendando o jogo: futebol amador e pelada na cidade e no sertáo. Tese (Doutorado em Sociologia) - UFPE, Recife, PE, 2009.

POLLAK, Michael. Memória, esquecimento, silêncio. Revista Estudos Históricos, Rio de Janeiro, v. 2, n. 3, p. 3-15, 1989.

. Memória e identidade social. Revista Estudos Históricos, Rio de Janeiro, v. 5, n. 10, p. 200-2015, 1992.

PORTELLI, Alessandro. Ensaios de história oral. São Paulo: Letra e Voz, 2010. p. 131-158.

SANTOS, Joel Rufino dos. História politica do futebol brasileiro. São Paulo: Brasiliense, 1981.

SILVA, Diana Mendes Machado da. Futebol de várzea em São Paulo: a Associação Atlética Anhanguera (1928-1940). São Paulo: Alameda, 2016.

THOMPSON, Paul. A voz do passado. São Paulo: Paz e Terra, 1992.

TOLEDO, Luiz Henrique de. Futebol e teoria social: aspectos da produção científica brasileira (1982-2002). Revista Brasileira de Informação Bibliográfica em Ciências Sociais, n. 52, p. 133-165, 2002. 
TONINI, Marcel Diego. Dentro e fora dos gramados: histórias orais de vida de futebolistas brasileiros negros no continente europeu. Tese (Doutorado em História Social) -USP, São Paulo, SP, 2016.

WISNIK, José Miguel. Veneno remédio: o futebol e o Brasil. São Paulo: Companhia das Letras, 2008.

\section{Fontes Orais}

CAMPOS, José Maciel [58 anos]. [jun. 2017]. Entrevistador: Raphael Rajāo Ribeiro. Belo Horizonte, MG, 1 jun. 2017.

COELHO, Márcio Antônio [62 anos]. [mai. 2016]. Entrevistador: Raphael Rajão Ribeiro. Belo Horizonte, MG, 2 mai. 2016.

COSTA, Eliana da Conceição [62 anos]. [mar. 2017]. Entrevistador: Raphael Rajão Ribeiro. Belo Horizonte, MG, 10 mar. 2017.

LIMA, Jorgeval Costa [59 anos]. [abr. 2017]. Entrevistador: Raphael Rajão Ribeiro. Belo Horizonte, MG, 8 abr. 2017.

ROCHA, Edval Gomes da [51 anos]. [abr. 2017]. Entrevistador: Raphael Rajão Ribeiro. Belo Horizonte, MG, 8 abr. 2017.

PEREIRA, Rosalvo Conceição [78 anos]. [mar. 2016]. Entrevistador: Raphael Rajão Ribeiro. Belo Horizonte, MG, 29 mar. 2016.

SANTOS, Guilherme Ferreira dos [68 anos]. [abr. 2016]. Entrevistador: Raphael Rajão Ribeiro. Belo Horizonte, MG, 7 abr. 2016.

SOUZA, Gemir de [89 anos]. [jun. 2016]. Entrevistador: Raphael Rajāo Ribeiro. Belo Horizonte, MG, 24 jun. 2016.

SOUZA, Sebastiāo Bento de [75 anos]. [abr. 2016]. Entrevistador: Raphael Rajão Ribeiro. Belo Horizonte, MG, 15 abr. 2016.

Resumo: Este artigo apresenta o processo de reivindicação de jogadores e clubes não profissionais por espaços urbanos para a prática do "fute- 
bol de várzea”, modalidade amadora existente na capital mineira de Belo Horizonte. Por meio desse estudo de caso, visamos mostrar novas facetas do universo esportivo brasileiro, tais como narrados oralmente por seus atores anônimos e por suas respectivas entidades associativas, capazes de propor dimensôes comunitárias menos usuais de abordagem, quando comparadas à imagem internacional do "país do futebol". A demonstração vale-se de fontes e métodos hauridos da História Oral, cujo histórico de desenvolvimento no Brasil é aqui apresentado à guisa de contextualização. Com o mesmo intento, o texto aborda de forma panorâmica a introdução dos estudos futebolísticos no país, desde os idos de 1970, quando a temática não era reconhecida no meio acadêmico, até a contemporaneidade, no momento que pesquisas sobre o tema avultam, com significativo alcance qualitativo e quantitativo.

Palavras-chave: História Oral no Brasil. Práticas esportivas. Futebol brasileiro. Território, identidade e conflito.

\title{
Oral History, football practice and Brazilian cities: conflicts and appropriations in the occupation narratives of Belo Horizonte's (MG) amateur soccer fields
}

\begin{abstract}
This paper presents the process of non-professional players and clubs claiming urban spaces for the practice of "várzea football", an amateur football mode existing in different cities, including the state capital of Minas Gerais, Belo Horizonte. Through this case study we aim to show new facets of the Brazilian sports universe, according to the oral narrations by anonymous actors and their respective associative entities. Which were capable of proposing approaches to community dimensions that are uncommon when compared to the international image of the "country of football". This demonstration uses sources and methods based on Oral History and whose history of development in Brazil is contextualized in this article. With the same intent, this paper presents an overview of the introduction of football studies in the country from the 1970s, when the theme was not recognized in the academia, to contemporaneity, a period when research on the topic grows with significant qualitative and quantitative range.
\end{abstract}

Keywords: Brazilian Oral History. Sports practices. Brazilian football. Territory, identity and conflict.

Recebido em 15/07/19

Aprovado: em 13/10/19 